\title{
Author's Reply to Parsons: "Cytotoxicity of Oxycodone and Morphine in Human Neuroblastoma and Mouse Motoneuronal Cells: A Comparative Approach"
}

\author{
Merja Kokki $^{1,2} \cdot$ Markku Pasanen $^{3} \cdot$ Hannu Kokki ${ }^{1,2}$
}

Published online: 25 May 2016

(c) The Author(s) 2016. This article is published with open access at Springerlink.com

We would like to thank Professor Parsons for his interest and comments concerning our manuscript "Cytotoxicity of Oxycodone and Morphine in Human Neuroblastoma and Mouse Motoneuronal Cells: A Comparative Approach" [1]. We totally agree with Parsons that the choice of appropriate cell model is of paramount importance in in vitro drug toxicity testing [2]. Moreover, using at least two cell lines and two toxicity assays is endorsed in order to have more accurate and relevant interpretation of drug toxicity for clinical use. In our study, we have used the SHSY5Y and NSC-34 cell lines, and 3-(4,5-dimethylthiazole2-yl)-2,5-diphenyltetrazolium bromide (MTT) and resazurin reduction assays, all of which are commonly used for assessing the toxicity of different compounds. In the present study, the toxicity of both compounds, oxycodone and morphine, appeared to be similar in both cell lines and both assays.

The main focus of the letter to the editor by Parsons is that the two cell lines used in our study were not differentiated prior to neurotoxicity testing. Use of transformed cell lines is a widely used approach in scientific literature

Hannu Kokki

hannu.kokki@uef.fi

1 Anaesthesiology and Intensive Care Medicine, School of Medicine, University of Eastern Finland, Kuopio, Finland

2 Department of Anesthesia and Operative Services, Kuopio University Hospital, PO Box 100, 70029 KYS Kuopio, Finland

3 School of Pharmacy, University of Eastern Finland, Kuopio, Finland to get 'quick answers for easy questions'. We are not claiming that the cell models used were the most optimal. However, these two cell lines, the SH-SY5Y and NSC-34 cell lines, are widely used and were available on our campus. Moreover, we have expertise for resazurin and classical MTT tests, both commonly accepted as accurate methods in this kind of evaluation. In this study, the first endpoint tested was cell viability. Both cell lines resulted in a comparable outcome for 'toxic' concentrations, which were well above those reached in clinical work. Therefore, further studies were carried out with SH-SY5Y cells only, which are routinely used in in vitro neurotoxic studies. Based on the PubMed search, $>620$ studies targeting neurotoxicity as an endpoint have been carried out with $\mathrm{SH}-$ SY5Y cells thus far. Our proof-of-concept data should be considered as preliminary 'kick-offs' for further studies with additional cell signaling, 'omics', or any other more specific endpoints. For more conclusive studies, more relevant differentiated cell lines of human origin should be used as proposed by Parsons.

We agree with Parsons that the results based on in vitro cell models may not replicate in vivo phenotypes [2], and thus, as we wrote, ideally a complete roster of histologic, physiologic, and behavioral testing should be performed on spinal drugs in two or more animal species, followed by safety trials in humans prior to widespread clinical use [1].

In conclusion, the results of our study [1] should be considered as preliminary data on the neurotoxicity of epidural oxycodone. The data support our clinical experience with several decades of epidural infusion of oxycodone in palliative care and our study hypothesis that neurotoxicity of oxycodone may not be inferior to that of morphine. However, further studies and close follow-up of 
patients are required for epidural pain management in the most vulnerable patient groups.

\section{Compliance with Ethical Standards}

Author Merja Kokki has no conflict of interest to declare. Author Markku Pasanen has no conflict of interest to declare. Author Hannu Kokki has no conflict of interest to declare.

Open Access This article is distributed under the terms of the Creative Commons Attribution-NonCommercial 4.0 International License (http://creativecommons.org/licenses/by-nc/4.0/), which permits any noncommercial use, distribution, and reproduction in any medium, provided you give appropriate credit to the original author(s) and the source, provide a link to the Creative Commons license, and indicate if changes were made.

\section{References}

1. Kokki M, Pesonen M, Vehviläinen P, Litmala O, Pasanen M, Hokki H. Cytotoxicity of oxycodone and morphine in human neuroblastoma and mouse motoneuronal cells: a comparative approach. Drugs R D. 2016;16(2):155-63. doi:10.1007/s40268016-0125-0.

2. Parsons RD. The use of clinically-relevant in vitro models for drug toxicity studies-what constitutes a clinically-relevant in vitro model? Drugs R D. 2016. [Submitted]. 